\title{
Hemilaminectomy and Bilateral Decompression for Thoracic Spinal Stenosis
}

\author{
Abdulfettah TUMTURK' ${ }^{1}$, Mehmet MERAL ${ }^{2}$, Ahmet KUCUK ${ }^{1}$, Halil ULUTABANCA ${ }^{1}$, Rahmi Kemal KOC ${ }^{1}$ \\ ${ }^{1}$ Erciyes University Medical Faculty, Department of Neurosurgery, Kayseri, Turkey \\ ${ }^{2}$ Erciyes Hospital, Department of Neurosurgery, Kayseri, Turkey \\ This study has been presented at the $33^{\text {rd }}$ Annual Scientific Meeting of Turkish Neurosurgical Society between 11 and 14 April 2019 at Antalya, Turkey.
}

Corresponding author: Rahmi Kemal KOC kocrk@erciyes.edu.tr

\section{ABSTRACT}

AIM: To assess the effectiveness and reliability of hemilaminectomy and bilateral decompression (HLBD) for the treatment of thoracic spinal stenosis (TSS) in selected patients.

MATERIAL and METHODS: Clinical data of 21 consecutive adult patients who underwent HLBD were investigated. Patients diagnosed with TSS by computed tomography or magnetic resonance imaging, with stenosis secondary to posterior element hypertrophy, and who underwent HLBD for the treatment of narrow spinal canal were included in this study. Patients were evaluated based on their pre- and postoperative modified Japanese Orthopedic Association (JOA) scores using their medical records. Recovery rates were evaluated using the Hirabayashi's method.

RESULTS: The mean follow-up period, age, and preoperative JOA score were 37.6 months, 61.6 years, and 5.0 (range: 1-10), respectively. The mean JOA score improved postoperatively, i.e., 10.0 (range: 7-11), during follow-up. The recovery rate was 83.3\%. Operation-related transfusion, neurological deterioration, and postoperative instability did not occur during the follow-up examination.

CONCLUSION: HLBD is a suitable surgical technique for patients with stenosis primarily caused by posterior element hypertrophy, such as ligamentum flavum (LF) and facet joints because it has a relatively less complication ratio, protects the posterior anatomical structures, prevents post-laminectomy kyphosis and postoperative instability, and promotes successful clinical improvement.

KEYWORDS: Bilateral decompression, Hemilaminectomy, Thoracic spinal stenosis

\section{INTRODUCTION}

T Thoracic spinal stenosis (TSS), characterized by narrowing of the anteroposterior diameter of the spinal canal, causes both spinal cord compression and onset of clinical symptoms (11). The thoracic spine is relatively stable due to the structural support of the ribs and its limited movement capacity (5). Hence, degenerative changes, i.e., TSS, rarely occur (23).

Thickened and/or ossified ligamentum flavum (T/OLF) is the most common cause of TSS (7) and frequently occurs in the lower thoracic region (2). Other degenerative causes of TSS are ossified posterior longitudinal ligament (OPLL), facet hypertrophy, osteophyte formation, and thoracic disc hernias. This is a slowly progressive and insidious degenerative disease that presents itself usually with myelopathy and mostly afflicts the elderly population $(2,6)$. Clinically catastrophic initial presentations are also possible (17). Although computed tomography (CT) and magnetic resonance imaging (MRI) are the most commonly used imaging technique for the diagnosis of TSS (5), it is mainly diagnosed based on its clinical course.
Abdulfettah TUMTURK (1) : 0000-0001-5883-9819

Mehmet MERAL (1) : 0000-0003-3814-3528

Ahmet KUCUK (1):0000-0002-9198-9605
Halil ULUTABANCA (10): 0000-0001-5912-3222

Rahmi Kemal KOC (D) : 0000-0001-9928-0468 
Surgery is the preferred treatment of choice for patients with symptomatic spinal cord compression, in order to decompress the spinal cord. Surgical interventions include posterior and anterior approaches, sometimes both. However, decompression surgery carries risk of neurological deterioration in both approaches $(3,21,22)$. The traditional treatment for TSS secondary to T/OLF is laminectomy. However, this treatment has disadvantages such as spinal deformity and instability, acceleration of spondylotic changes, post-laminectomy membrane and dura constriction due to epidural cicatrices and adhesions, and lack of posterior bony protection of the spinal cord during follow-up (13). To avoid these complications, our patients were treated with HLBD.

\section{MATERIAL and METHODS}

From March 2010 to December 2017, 21 patients who underwent surgical treatment for TSS were enrolled in this study. Among 21 included patients, 13 were men and 8 were women, with the mean age of 61.6 (range: $41-78$ ) years.

Patients with sensation or motor dysfunction found in the lower limbs, diagnosed with TSS as confirmed by CT or MRI, with stenosis secondary to hypertrophy on the posterior elements, and who underwent HLBD for the treatment of narrow spinal canal were included in this study.

Those with thoracic disc herniations (when it is the only cause of stenosis), osteophyte formation, OPLL, and other reasons such as tumor or tuberculosis, ankylosing spondylitis, and serious inflammatory diseases were excluded from the study. Patients with co-existing spinal disorders including lumbar and cervical stenosis were also treated during the same session. Neurological condition was assessed by using modified Japanese Orthopedic Association (JOA) scale score (4). Scores of the upper extremities were excluded, and full score was 11 points for normal patients (Table I). The postoperative recovery rate was calculated using the Hirabayashi method (8). Recovery rate (\%) = (postoperative JOA-preoperative JOA) / (11-preoperative JOA) $\times$ 100. The last follow-up JOA score of patients was used for calculation.

Surgical procedure: Under general anesthesia and in prone position, all patients underwent posterior decompression surgery via bilateral decompression with unilateral approach. Under microscopic visualization, the ipsilateral laminae at the upper and lower segments were partially removed using a high-speed drill and Kerrison punch. The ipsilateral LF was carefully resected. To avoid dural injury, flavectomy was performed from the midline and expanded laterally. To avoid neural injury, decompression was completed on the hemilaminectomy site. Then, the contralateral side was decompressed. By medial angulation of the microscope, the base of the spinous process was undercut and the contralateral lamina was partially removed using a highspeed drill, Kerrison punch, and curette. The contralateral LF was resected. The lateral margin of the decompression was restricted at the pedicle in each level. Hypertrophied facet was drilled to limit the width to its medial one-third to avoid instability. T/OLF was carefully removed from the dura. A
Table I: Modified JOA Score for Thoracic Myelopathy

\begin{tabular}{|c|c|}
\hline Category & Score \\
\hline \multicolumn{2}{|l|}{ A. Lower extremity motor function } \\
\hline Unable to stand up and walk by any means & 0 \\
\hline $\begin{array}{l}\text { Unable to walk without a cane or other } \\
\text { support on a level }\end{array}$ & 1 \\
\hline $\begin{array}{l}\text { Walks independently on a level but needs } \\
\text { support on stairs }\end{array}$ & 2 \\
\hline Capable of fast walking but clumsy & 3 \\
\hline Normal & 4 \\
\hline \multicolumn{2}{|l|}{ B. Sensory function } \\
\hline \multicolumn{2}{|l|}{ I. Lower extremity } \\
\hline Apparent sensory loss & 0 \\
\hline Minimal sensory loss & 1 \\
\hline Normal & 2 \\
\hline \multicolumn{2}{|l|}{ II. Trunk } \\
\hline Apparent sensory loss & 0 \\
\hline Minimal sensory loss & 1 \\
\hline Normal & 2 \\
\hline \multicolumn{2}{|l|}{ C. Bladder function } \\
\hline Urinary retention and/or incontinence & 0 \\
\hline $\begin{array}{l}\text { Sense of retention and/or dribbling and/or } \\
\text { thin stream }\end{array}$ & 1 \\
\hline Urinary retardation and/or pollakiuria & 2 \\
\hline Normal & 3 \\
\hline
\end{tabular}

Total score for normal patient is 11 .

wide partial hemilaminectomy including one level above and below the T/OLF was performed. No intraoperative surgical complication such as dural injury occurred. The clinical and surgical data obtained from patients' medical records are summarized in Table II and sample case is provided in Figure $1 \mathrm{~A}, \mathrm{~B}$.

All patients signed informed consents to voluntarily participate in this study, and the Institutional Ethics Committee of Erciyes University Medical Faculty approved this study (Date: 19.12.2018; No: 2018/650).

\section{Statistical Analysis}

Wilcoxon signed ranktest was used to compare the score levels pre- and postoperatively. Statistical analyses were performed using TURCOSA Analytics Ltd Co, Turkey (www.turcosa.com. tr). Two-tailed $p$-values of $p<0.05$ were considered statistically significant. 
Table II: Summary of the Clinical Data Obtaine from Medical Records of the Patients

\begin{tabular}{|c|c|c|c|c|c|c|c|}
\hline Case & Age, Sex & Signs/Symptoms & $\begin{array}{l}\text { mJOA } \\
\text { Preop }\end{array}$ & $\begin{array}{l}\text { mJOA } \\
\text { Postop }\end{array}$ & $\begin{array}{l}\text { Stenotic } \\
\text { Levels }\end{array}$ & $\begin{array}{l}\text { Co-Existing } \\
\text { Stenosis }\end{array}$ & $\begin{array}{l}\text { Follow } \\
\text {-up }\end{array}$ \\
\hline 1 & $70, \mathrm{M}$ & $\begin{array}{l}\text { Lower limbs weakness, numbness, gait disturbance } \\
\text { urinary incontinence }\end{array}$ & 3 & 8 & $\mathrm{~T} 10-11, \mathrm{~T} 11-12$ & C5-6 & 30 \\
\hline 2 & $56, \mathrm{M}$ & Lower limbs weakness, numbness, gait disturbance & 4 & 11 & $\mathrm{~T} 11-12$ & C2-7, L4-5 & 18 \\
\hline 3 & $61, \mathrm{M}$ & Lower limbs numbness, burning, leg and back pain & 8 & 11 & $\mathrm{~T} 11-12$ & C3-6, L4-5 & 24 \\
\hline 4 & $64, \mathrm{~F}$ & Lower limbs weakness, numbness & 8 & 11 & T10-11 & L3-4 & 30 \\
\hline 5 & $55, F$ & Gait disturbance & 9 & 11 & $\mathrm{~T} 10-11$ & L3-4 (T) & 18 \\
\hline 6 & $78, \mathrm{M}$ & Lower limbs weakness & 6 & 9 & $\mathrm{~T} 10-11$ & $\mathrm{~L} 2-3(\mathrm{~T})$ & 42 \\
\hline 7 & $73, \mathrm{M}$ & Gait disturbance, numbness, urinary incontinence & 1 & 8 & T7-8 & L2-3 & 54 \\
\hline 8 & $59, \mathrm{~F}$ & $\begin{array}{l}\text { Lower limbs weakness, numbness, urinary } \\
\text { incontinence }\end{array}$ & 3 & 10 & $\mathrm{~T} 11-12$ & & 25 \\
\hline 9 & $63, F$ & $\begin{array}{l}\text { Gait disturbance, numbness, burning, urinary } \\
\text { incontinence }\end{array}$ & 7 & 10 & $\mathrm{~T} 10-11$ & & 78 \\
\hline 10 & $61, \mathrm{M}$ & Lower limbs weakness & 9 & 11 & $\mathrm{~T} 11-12$ & C3-6 & 90 \\
\hline 11 & $62, \mathrm{~F}$ & Leg pain & 9 & 11 & $\mathrm{~T} 10-11, \mathrm{~T} 11-12$ & & 54 \\
\hline 12 & $60, \mathrm{M}$ & Gait disturbance & 3 & 7 & T9-10 & C4-5,C5-6 & 19 \\
\hline 13 & $66, \mathrm{~F}$ & Back pain and leg pain & 10 & 11 & $\mathrm{~T} 11-12$ & $\mathrm{~L} 2-3(\mathrm{~T})$ & 41 \\
\hline 14 & $65, M$ & Gait disturbance (needs a cane) & 5 & 11 & $\mathrm{~T} 10-11$ & & 78 \\
\hline 15 & $43, \mathrm{M}$ & Gait disturbance, numbness, urinary incontinence & 3 & 11 & $\mathrm{~T} 1-2, \mathrm{~T} 2-3$ & & 19 \\
\hline 16 & $66, \mathrm{M}$ & Gait disturbance, numbness, leg pain & 7 & 9 & $\mathrm{~T} 10-11$ & L2-3, L3-4 & 26 \\
\hline 17 & $69, \mathrm{~F}$ & Back pain, leg pain & 10 & 11 & $\mathrm{~T} 11-12$ & L3-4 (T) & 22 \\
\hline 18 & $58, \mathrm{M}$ & Back pain, leg pain, numbness, urinary incontinence & 5 & 10 & T12-L1 & L3-4 (T) & 18 \\
\hline 19 & $41, \mathrm{M}$ & $\begin{array}{l}\text { Lower limbs weakness, numbness, burning, } \\
\text { urinary incontinence }\end{array}$ & 4 & 9 & $\mathrm{~T} 10-11, \mathrm{~T} 11-12$ & & 70 \\
\hline 20 & $61, \mathrm{~F}$ & Lower limbs weakness, numbness, leg pain & 4 & 8 & $\mathrm{~T} 11-12$ & & 21 \\
\hline 21 & $72, \mathrm{M}$ & Lower limbs weakness, numbness, gait disturbance & 5 & 10 & T12-L1 & & 12 \\
\hline
\end{tabular}

mJOA: Modified Japanese Orthopedic Association Score, T: Tandem operation.

\section{RESULTS}

The mean follow-up period and age were 37.6 (range: 12-90) months and 61.6 (range: 34-78) years. The median preoperative JOA score was 5.0 (range: 1-10), where as the postoperative JOA score was 10.0 (range: 7-11) with statistically significant differences $(p<0.001)$.

The best and early recovery was seen in motor functions, followed by sensory and bladder functions, respectively. The mean recovery rate was $83.3 \%$. In this study, any surgical wound infection did not occur. There was also no operation-related transfusion and neurological deterioration. Any operation-related instability was not detected during the follow-up examination. Adequate decompression was observed in the MRI at 3-month follow-up.
Among 21 patients, five underwent concomitant spinal surgery for lumbar spinal canal stenosis. According to patient's history, eight had been operated previously: three for cervical spondylotic myelopathy, three for lumbar spinal canal stenosis, and two for both as shown in Table II. As a result, $48 \%$ of patients with TSS were accompanied by lumbar stenosis and $24 \%$ of were accompanied by cervical stenosis.

\section{DISCUSSION}

Spinal stenosis commonly occurs in the lumbar and cervical region (16). Since the thoracic vertebral column is relatively stable, spinal stenosis is seen exceedingly rare in this region $(11,16)$. TSS develops mainly based on ventral compression of the spinal cord due to thoracic disc hernias, posterior osteophyte bars, OPLL, and dorsal/dorsolateral compression 

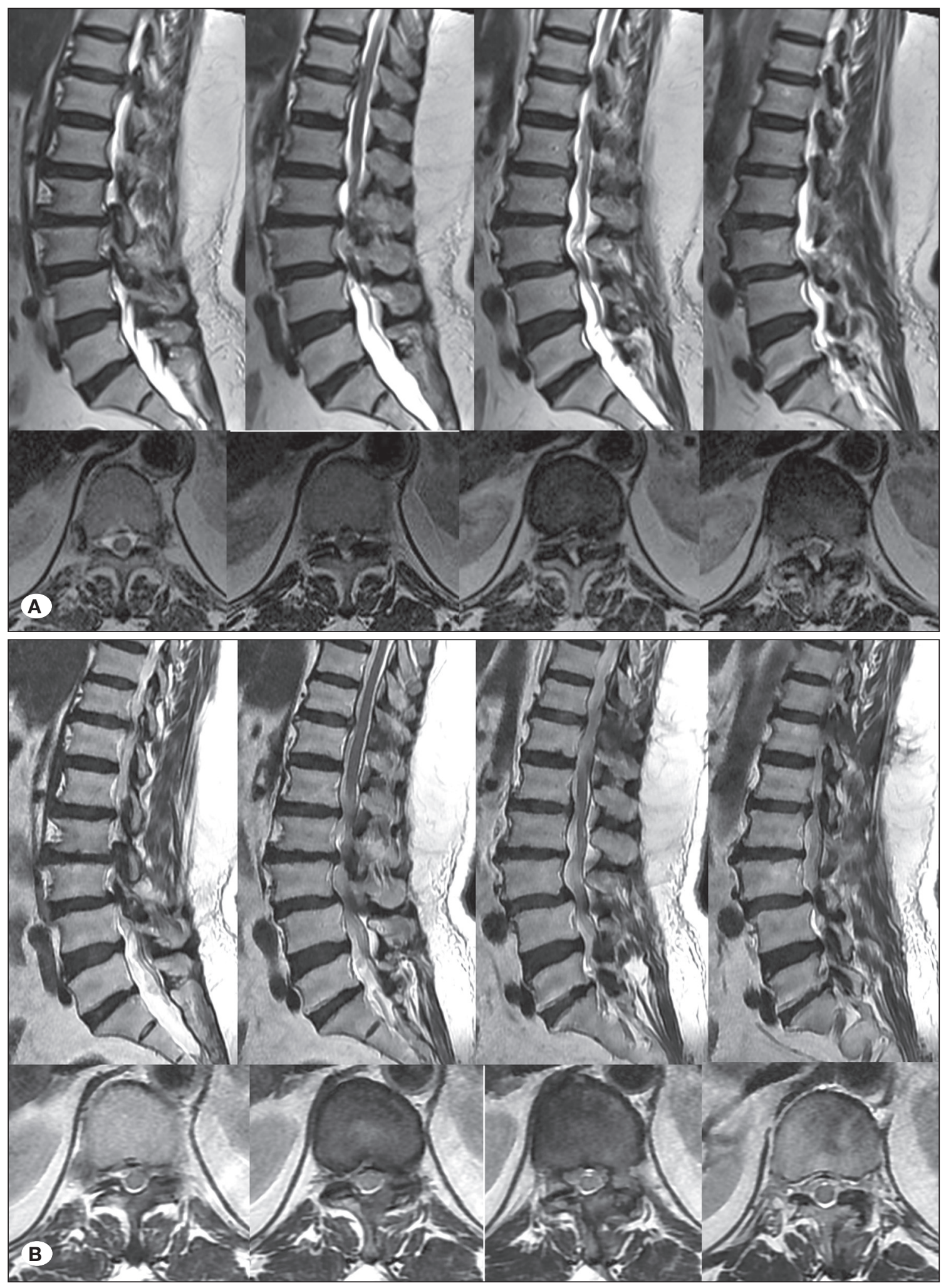

Figure 1: A 41-year-old man presented with a 3-year history of progressive tingling and burning sensations and weakness in his lower limbs (he needs support when walking) and urinary incontinence (Case19). On neurological examination, the strength of his lower extremities is $3 / 5$. Sensory deficit of $<\mathrm{T} 12$ was noted, and his lower extremity reflexes were hyperactive. His preoperative JOA score was 4 (A). T2W sagittal and axial MR images showed a thoracic stenosis at T11-T12 level. On the 4-month follow-up examination after surgical procedure, walking support was discontinued and complaints of urinary incontinence were partially resolved. His postoperative JOA score was 9. Sagittal and axial T2W MR images showed adequate decompression at T11-T12 level (B). 
caused by facet joint and LF hypertrophy (2). In some cases, LF can also be calcified (1). Combination of these may also be the cause.

Stenosis of the vertebral canal resulting in neural compression and onset of clinical manifestations commonly is characterized by signs and symptoms of myelopathy and rarely radiculopathy or both $(9,11)$.

In general, this is a slowly progressing disease, and thus, its clinical symptoms tend to start following a minor or moderate trauma and its clinical course tends to be more abrupt onset in case of trauma $(7,9)$. In this series, only one patient $\left(9^{\text {th }}\right.$ patient) had a history of minor trauma. This patient presented a poor preoperative JOA score.

Ossified LF is reported as the common cause of TSS and frequently observed at the lower thoracic region $(2,9)$. Out of 21 patients included in this study, 13 had TSS because of ossified LF; 19 had stenosis in the lower thoracic region (T9T12); one had stenosis in the upper thoracic spine (T1-T2), the second most common site; and one in the middle thoracic spine (T7-T8).

Selection of appropriate surgical technique plays a critical role in favorable postoperative outcomes. Other than this, postoperative neurological deterioration may also originate from insufficient decompression (7). Several surgical techniques were available for the treatment of TSS such as anterior, posterolateral, and posterior decompression of the spinal cord with or without instrumentation and fusion. The surgical technique is selected according to the compression site $(9,16,19,21)$.

Anterior surgery is commonly used for ventrally compressed spinal cords $(6,9,11)$. Laminoplasty, laminectomy with or without instrumentation, and hemilaminectomy procedures have been considered as the appropriate surgical techniques for patients with dorsally compressed spinal cord $(2,6,11,14,15,20,22)$. No patient had giant or large calcified disk that ventrally compressed the spinal cord and who had tenuous spinal cord in this study. These patients are not indicated for HLBD due to the high risk of neural injury. Patients with stenosis due to hypertrophy on the posterior elements were included in this study.

Laminectomy is the common technique for the treatment of TSS related to posterior element hypertrophy. However, it has disadvantages such as post-laminectomy kyphosis, postoperative instability, and postoperative scar formation (14). When these occur, posterior decompression may be ineffective.

The goal of the surgery is to achieve an adequate decompression without causing neural injury and destabilization (18). In accordance with this goal, HLBD prevents destabilization and minimizes postoperative scar formation. With a limited surgical dissection, blood loss, infection rate, postoperative pain, and hospital stay are also decreased. In order to thin out hypertrophied facet and lamina, a high-speed drill should be used, instead of foot-plated surgical instruments in the stenotic segment to prevent spinal cord injury (12).

The best and early recovery was seen in motor functions, followed by sensory functions. The bladder function was recovered less than others.

One stage surgery was reported to be effective in tandem stenosis by $\mathrm{Hu}$ et al. (10). Patients in this study are well satisfied with the surgery. We thought that this occurs due to the limited muscle dissection and short operation time. Furthermore, due to the short operation time, surgery for other stenotic segments was performed simultaneously, an also important factor for patient satisfaction.

Blood transfusion was not required, and surgical wound infection was not observed as a result of limited dissection. No dural tear and CSF leakage occurred. Ossified LF can sometimes adhere to the dura. Dural adhesion occurs only when LF ossification progresses to its deep layer. During the surgical procedures in patients of this series, no patient had LF ossification that progressed to its deep layer and adhered to the dura. However, ossification along the superficial layer of the hypertrophied LF was observed. Dural calcification also rarely occurs. No hypointense rim showing dural calcification in T2-weighted MRI was detected in any of our patients. Stenosis was mainly related to hypertrophied and superficially ossified LF, and no dural calcification was observed in all patients.

Dural injury did not occur because LF ossification extended along the superficial layer of LF, and stenosis was related to thickened LF without dural calcification.

No postsurgical instability was observed in the follow-up period. We thought this was related to the fact that posterior elements were preserved and the width of the facet did not exceed its medial one-third while drilling the hypertrophied facet to avoid instability.

\section{CONCLUSION}

Although different surgical techniques are available for the management of TSS, HLBD is a suitable technique for patients with stenosis primarily due to hypertrophy on the posterior elements because it has a relatively less complication ratio, protects the posterior anatomical structures, prevents postlaminectomy kyphosis and postoperative instability, and promotes successful clinical improvement. The success of this technique depends on proper patient selection; however, it should not be indicated for patients with ventrally compressed spinal cord. Coexisting spinal cord disorders should be treated simultaneously to promote postoperative patient satisfaction.

\section{ACKNOWLEDGEMENTS}

Preparation for publication of this article is partly supported by "Turkish Neurosurgical Society" 


\section{REFERENCES}

1. Aizawa T, Sato T, Sasaki H, Kusakabe T, Morozumi N, Kokubun S: Thoracic myelopathy caused by ossification of the ligamentum flavum: Clinical features and surgical results in the Japanese population. J Neurosurg Spine 5:514-519, 2006

2. Aizawa $T$, Sato $T$, Tanaka $Y$, Ozawa H, Hoshikawa $T$, Ishii $Y$, Morozumi N, Ishibashi K, Kasama F, Hyodo H, Murakami E: Thoracic myelopathy in Japan: Epidemiological retrospective study in Miyagi Prefecture during 15 years. Tohoku J Exp Med 210:199-208, 2006

3. Barnett GH, Hardy RW, Little JR, Bay JW, Sypert GW: Thoracic spinal canal stenosis. J Neurosurg 66:338-344, 1987

4. Benzel EC, Lancon J, Kesterson L, Hadden T: Cervical laminectomy and dentate ligament section for cervical spondylotic myelopathy. J Spinal Disord 4:286-295, 1991

5. Cowley P: Neuroimaging of spinal canal stenosis. Magn Reson Imaging Clin N Am 24:523-539, 2016

6. Epstein N, Schwall G: Thoracic spinal stenosis-diagnosis and treatment challenges. J Spinal Disord 7:259-269, 1994

7. Fong SY, Wong HK: Thoracic myelopathy secondary to ligamentum flavum ossification. Ann Acad Med Singapore 33:340-346, 2004

8. Hirabayashi K, Miyakawa J, Satomi K, Maruyama T, Wakano $\mathrm{K}$ : Operative results and postoperative progression of ossification among patients with ossification of cervical posterior longitudinal ligament. Spine 6:354-364, 1981

9. Hou X, Sun C, Liu X, Liu Z, Qi Q, Guo Z, Li W, Zeng Y, Chen $Z$ : Clinical features of thoracic spinal stenosis-associated myelopathy: A retrospective analysis of 427 cases. Clin Spine Surg 29:86-89, 2016

10. Hu P, Yu M, Liu X, Liu Z, Jiang L, Chen Z: One-staged combined decompression for the patients with cervico-thoracic tandem spinal stenosis. Eur Spine J 26:374-381, 2017

11. Kalfas IH: Laminectomy for thoracic spinal canal stenosis. Neurosurg Focus 9: E2, 2000

12. Kim JS, Jung B, Arbatti N, Lee SH: Surgical experience of unilateral laminectomy for bilateral decompression (ULBD) of ossified ligamentum flavum in the thoracic spine. Minim Invas Neurosurg 52:74-78, 2009
13. Menku A, Koc RK, Oktem IS, Tucer B, Kurtsoy A: Laminoplasty with miniplates for posterior approach in thoracic and lumbar intraspinal surgery. Turk Neurosurg 20:27-32, 2010

14. Okada K, Oka S, Tohge K, Ono K, Yonenobu K, Hosoya T: Thoracic myelopathy caused by ossification of the ligamentum favum. Spine 16:280-287, 1991

15. Ozdemir N, Yaman O, Dalbayrak S, Temiz C, Acar E, Dagli AT: Comparison of bilateral decompression via unilateral approach and classic laminectomy in patients with lumbar spinal stenosis: A retrospective clinical study. Turk Neurosurg 25:239-245, 2015

16. Palumbo MA, Hilibrand AS, Hart RA, Bohlman HH: Surgical treatment of thoracic spinal stenosis. Spine 26:558-566, 2001

17. Saetia K, Cho D, Lee S, Kim DH, Kim SD: Ossification of the posterior longitudinal ligament: A review. Neurosurg Focus 30:E1, 2011

18. Spetzger U, Bertalanffy $H$, Reinges MT, Gilsbach JM: Unilateral laminotomy for bilateral decompression of lumbar spinal stenosis Part II: Clinical experiences. Acta Neurochir (Wien) 139:397-403, 1997

19. Tomita KA, Kawahara NO, Baba HI, Kikuchi YU, Nishimura HI: Circumspinal decompression for thoracic myelopathy due to combined ossification of the posterior longitudinal ligament and ligamentum flavum. Spine 15:1114-1120, 1990

20. Wang T, Du C, Zheng X, Sun Y, Lıu X, Kou J: Surgical strategies for thoracic myelopathy due to ossification of ligamentum flavum: A technical note based on radiological type. Turk Neurosurg 28:616-624, 2018

21. Yamazaki M, Mochizuki M, Ikeda Y, Sodeyama T, Okawa A, Koda M, Moriya $\mathrm{H}$ : Clinical results of surgery for thoracic myelopathy caused by ossification of the posterior longitudinal ligament: Operative indication of posterior decompression with instrumented fusion. Spine 31:1452-1460, 2006

22. Yamazaki M, Okawa A, Koda M, Goto S, Minami S, Moriya $\mathrm{H}$ : Transient paraparesis after laminectomy for thoracic myelopathy due to ossification of the posterior longitudinal ligament. A case report. Spine 30:E343-E346, 2005

23. Young WF, Baron E: Acute neurologic deterioration after surgical treatment for thoracic spinal stenosis. J Clin Neurosci 8:129-132, 2001 